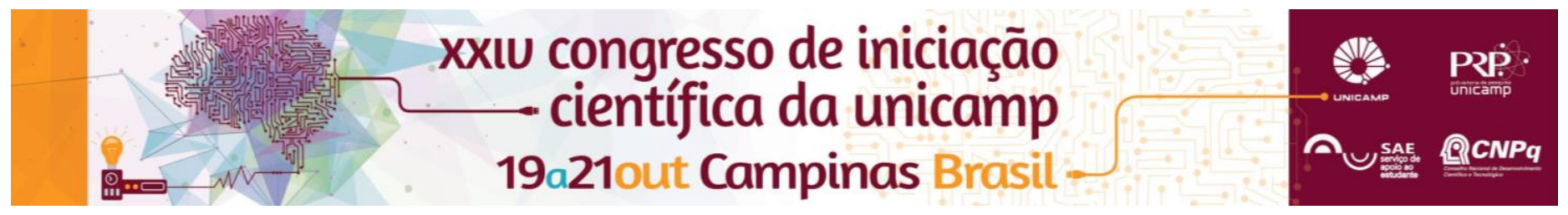

\title{
A experiência do Inventário: uma aventura pelos antigos laboratórios da EE "Culto à Ciência" de Campinas, de 1896 a 1942.
}

\author{
Matheus Rosa Paschoal e Prof.a Dra Maria Cristina Menezes
}

\begin{abstract}
Resumo
O projeto "A experiência do Inventário: uma aventura pelos antigos laboratórios da EE "Culto à Ciência" de Campinas, de 1896 a 1942", foi desenvolvido no âmbito do CIVILIS, Grupo de Estudos e Pesquisa em História da Educação, Cultura Escolar e Cidadania, FE/UNICAMP, coordenado pela Professora Maria Cristina Menezes. O projeto consistiu em conservar e descrever instrumentos científicos utilizados no ensino de física e química do Gymnásio de Campinas, de 1896 a 1942, presentes no acervo científico do arquivo histórico da E.E."Culto à Ciência". O processo de identificação e conservação de instumentos científicos foi viabilizado com o estudo de trabalhos realizados em instituições, nacionais e internacionais, visando o preenchimento de ficha de descrição articulada às fichas de descrição dos documentos manuscritos e dos manuais de ensino, dos acervos pertencentes ao arquivo histórico da instituição.
\end{abstract}

\section{Palavras-chave:}

Patrimônio Histórico-Educativo, Instrumentos Científicos, Cultura Material Escolar

\section{Introdução}

O foco principal deste projeto foi o desenvolvimento e o preenchimento de fichas de descrição dos instrumentos científicos dos antigos laboratórios, de Physica e Chimica, no período em que a EE "Culto a Ciência" permaneceu com a denominação de Gymnásio de Campinas, de 1896 a 1942. A Escola possui um arquivo histórico de grande importância para o conhecimento e o estudo da História da Educação e o objetivo da descrição de fichas articuladas, de documentos, livros e objetos, foi o de contribuir com os esforços de conservação e preservação desse acervo.

\section{Resultados e Discussão}

O projeto permitiu o contato com a "Cartilha de orientações gerais para a preservação do patrimônio cultural de ciência e tecnologia" desenvolvida pelo MAST, Museu de Astronomia/RJ, para a conservação de parte do acervo de instrumentos dos laboratórios de Physica e Chimica que se encontram, na sua maioria, em bom estado de preservação, embora estivessem distribuídas em vários armários sem as condições necessárias ao seu correto armazenamento. Quanto a isso, houve algum avanço na organização dos armários, mas ainda não foram atingidas as condições ideais.

A ficha catalográfica dos instrumentos sofreu diversas mudanças ao longo do projeto, para se adequar à descrição dos demais acervos do arquivo. Em versão final, além do nome, articulados ao Thesaurus de acervos científicos em língua portuguesa do MAST, foram descritos: função/funcionamento; país/ origem; fabricante; quantidade; dimensão; estado de conservação e foto; vínculos com os demais acervos do arquivo histórico com os quais compartilha as referências institucionais. As principais fontes de pesquisas foram o Catálogo del material antiguo de física y química del Museo Laboratório de História da Educação da Universidade Complutense de Madrid; manuais científicos do acervo bibliográfico da biblioteca histórica da escola, sobretudo, os manuais escritos pelos professores do Gymnásio de Campinas, além da ficha sugerida pela cartilha do MAST/RJ.

\section{Conclusões}

As conclusões, ainda que parciais, permitem listar ações importantes à formação do bolsista: revisão bibliográfica de autores nacionais e internacionais; contato com instrumentos científicos antigos e conhecimento de técnicas de conservação; preenchimento de fichas descritivas articuladas às fichas dos demais acervos da instituição, o que ocasionou contato com documentos manuscritos e antigos manuais científicos do arquivo histórico. Buscou-se ainda a validação de parte do acervo de instrumentos científicos com os itens que compõem o Thesaurus de acervos científicos de língua portuguesa, MAST/RJ. Cabe ressaltar a importância da criação de espaços adequados presenciais e virtuais de difusão do acervo, tal como as exposições realizadas pela equipe durante o projeto, para a comunidade interna e externa à instituição.

\section{Agradecimentos}

Nossos agradecimentos à Profa Maria Cristina Menezes, que possibilitou nosso ingresso na pesquisa científica acadêmica, nos incentivando e orientando com especial dedicação.

Agradecemos também ao PIBIC/SAE/UNICAMP pelo fomento da pesquisa.

GIRES, F. (Org) Physique Imperiále: catalogue réalisé sous la direction de Francis Gires emhommage à Jean Brossel (1918 - 2003). Disponível em:https://docs.google.com/file/d/0B8SmIfzGFoJzX3hYb2h3NHI4Sk0/edit?pli1 GRANATO, M; LOURENÇO, M. C. (Org.) Coleções científicas luso-brasileiras: patrimônio a ser descoberto. Rio de Janeiro: MAST, 2010. 362p. http://thesaurusonline.museus.ul.pt/default.aspx

GRANATO, M.; RIBEIRO, S. M.; CERAVOLO, S.; H ANDFAS, R. R.; Cartilha de orientações gerais para preservação do patrimônio cultural de ciência e ecnologia. Rio de Janeiro: MAST/MCTI, 2014.

SOMOZA, D V; VEJA, M R; SÁNCHEZ, M M. Catálogo del material antiguo de física y química del Museo Bartomé Cossio, Madri, 2014. Disponível em: $<\mathrm{http}$ ///pendientedemigracion.ucm.es/centros/cont/descargas/documento28961.p df 